\title{
$\widehat{A}$ Madridge \\ madridge Journal of Case Reports and Studies
}

Interconnecting Scientific World

Review Article

Open Access

\section{Kalonji Seeds (Nigella sativa) in Strengthening the Immune System}

\author{
Shehla Nazir', SM Arif Zaidi ${ }^{2}$, and Zehra Zaidi ${ }^{3 \star}$ \\ ${ }^{1}$ Assistant Professor, Department of Tashreeh-wa-Munafeul Aza, School of Unani Medical Education \& Research, Jamia Hamdard, New Delhi, India \\ ${ }^{2}$ Professor, Department of Jarahiyat, School of Unani Medical Education E Research, Jamia Hamdard, New Delhi, India \\ ${ }^{3}$ Assistant Professor, Department of Jarahiyat, School of Unani Medical Education E Research, Jamia Hamdard, New Delhi, India
}

\section{Article Info}

*Corresponding author:

\section{Zehra Zaid}

Assistant Professor

Department of Jarahiyat

School of Unani Medical Education \&

Research, New Delhi

India

E-mail: zehrazaidi786@ymail.com

Received: July 25, 2018

Accepted: August 21, 2018

Published: August 27, 2018

Citation: Nazir S, Arif Zaidi SM, Zaidi Z. Kalonji Seeds (Nigella sativa) in Strengthening the Immune System. Madridge J Case Rep Stud. 2018; 2(1): 55-56.

doi: $10.18689 /$ mjcrs-1000114

Copyright: @ 2018 The Author(s). This work is licensed under a Creative Commons Attribution 4.0 International License, which permits unrestricted use, distribution, and reproduction in any medium, provided the original work is properly cited.

Published by Madridge Publishers

\section{Introduction}

Kalonji/Shoniz (Nigella sativa) is a widely used medicinal plant having a history of thousands years. The plant is also in use as spice. The plant is an annual herb which is about 30 to $60 \mathrm{~cm}$ high and belongs to Ranunculaceae family. It has finely divided foliage and pale bluish purple or white flowers. The Black Seed forms a fruit capsule which consists of many white trigonal seeds. Once the fruit capsule has matured, it opens up and the seeds contained within are exposed to the air, becoming black in color.

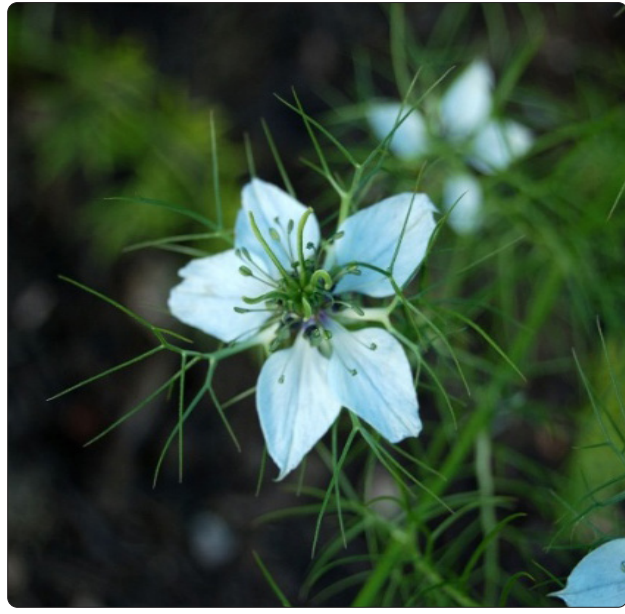

Plant of Kalonji (Nigella sativa)

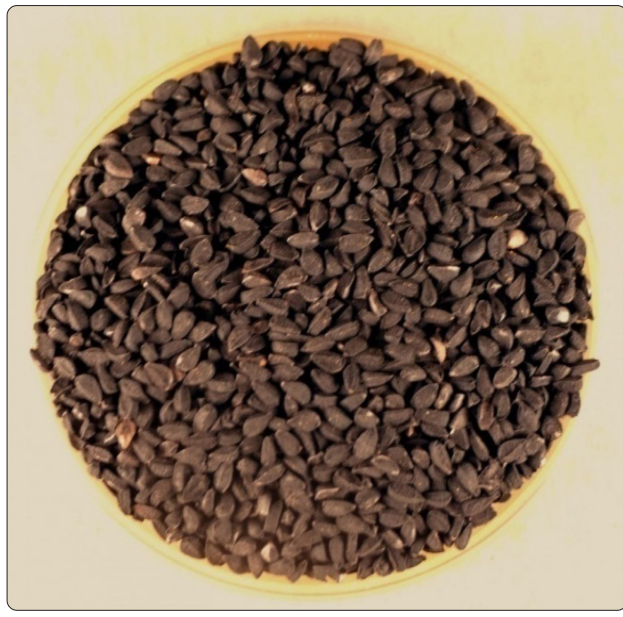

Seeds of Kalonji (Nigella sativa)
The Black seeds are small black grains with a rough surface and an oily white interior, similar to onion seeds. The seeds have little bouquet, though when rubbed, their aroma resembles oregano. They have a slightly bitter, peppery flavor and a crunchy texture.

\section{Vernacular Names of Kalonji seeds}

The Black seed is the common fennel flower plants (Nigella sativa) of the buttercup family. There are several common names attributed to Nigella sativa. These names differ between different regions and countries.

In Hindi it is known as Kalonji, Kalazeera, Mugrela, and Kalajera.

In Europe it is called black caraway, fennel-flower, nutmeg flower or sometimes "Love in the Mist"

In American it is called black cumin or black seed.

Its name in Egypt is Habbat ul Barka and in the rest of the Arabic world it is called Habbatul Sauda or Shoniz, Kamoon-e-Aswad. In Persian it is known as Siyah Dana, Shoniz, Siyah Daru, Shoniz, Shonoz and Siyah Biranj. 
In Sanskrit it is called as Bshpika, Kalajaji, karavi, Kunchi, Kunchika, Kunjika Musavi, Sthulajarika, Upakuncharika, Sushavi, Krishna-jiraka, Upakunchika. In Unani its name is Kalonji, Shoniz and in Urdu it is called as Kalonji.

The earliest written reference to Black seed is found in the book of Isiah in the old Testament.

\section{Uses of kalonji Seeds in Traditional Medicine}

In Greeco Arab / Unani Medicine Kalonji (Nigella sativa of Family-Ranunculaceae) is in use since Ist Century BC when Discoroides a Unani Physician and Botanist described Kalonji and its therapeutic use in his book.

The polysaccharide component is a good source of dietary fiber, which promotes the movement of bowels. The seeds are also rich in essential fatty acids such as Linoleic acid, which cannot be produced inside the body and need to be obtained from food. Black seed is a source of minerals like calcium, sodium, iron, and potassium and is thus important for the body.

\section{Biochemical Constituents}

Alanine, arginine, ascorbicbacid, asparagine, campesterol, carvone, cymene, cystine, dehydroascorbic-acid, eicosadienoic-acid, glucose, glutamic-acid, glycine, iron, isoleucine, leucine, d-limonene, linoleic-acid, linolenic-acid, lipase, lysine, methionine, myristic-acid, nigellin, nigellone, oleic-acid, Palmitic-acid, phenylalanine, phytosterols, potassium, beta-sitosterol, alphaspinasterol, stearic acid, stigmasterol, tannin, threonine, thymohydroquinone, thymoquinone, tryptophan, tyrosine.

\section{Pharmacological Studies}

[1]. Anti-Histaminic action:-Nigella sativa oil (black cumin seed oil) contains nigellone, which protects guinea pigs from histamine-induced bronchial spasms (perhaps explaining its use to relieve the symptoms of asthma, bronchitis, and coughing). Gilani AH et al 2001

[2]. The presence of the sterol beta-sitosterol lends credence to its traditional use to treat abscesses and tumors of the abdomen, eyes, and liver.

[3]. N. sativa oil has been reported to be effective in treating opiod dependence. (Sangi S et al 2008)

[4]. N. sativa also has been reported to reduce calculi formation in rats' kidneys. (Maryam Tehranipour and Nahid Monavar et al 2011)

[5]. Researchers at the Kimmel Cancer Center at Thomas Jefferson University in Philadelphia have found that thymoquinone from an extract of $\mathrm{N}$. sativa seed oil, blockedpancreatic cancer cell growth and killed the cells by enhancing the process of programmed cell death (apoptosis)acting as an HDAC inhibitor.

[6], [7]. In a comparative clinical study Nigella sativa steam inhalation has been found more effective than Chamomile in relieving symptoms of Chronic Bronchial Asthma. (Faruk H AlJawad et al 2012)

\section{Therapeutic uses}

Nigella sativa currently has five separate FDA patents in the U.S. and one in the UK for the treatment of

The aqueous decoction of Kalonji revealed significant antibacterial potential against Staphylococcus aureus, Micrococcus roseus, Streptococcus mutans, Streptococcus morbillorium, Streptococcus sanguis, Streptococcus intermedius, Klebsiella ozaenae, Aeromonas hydrophila, and Streptococcus salivarius. This study is correlated with the study carried out by Mashhadian \& Rakhshandeh (2005) in which Kalonji has been reported to inhibit Staphylococcus aureus, Ps. Aeruginosa and Candida albicans. (Nazia Masood Ahmed Chaudhry and Perween Tariq 2008).

N. sativa has a beneficial effect on fasting blood glucose, total cholesterol, and LDL cholesterol. More research is required to find out the various mechanisms by which $\mathrm{N}$. sativa acts on the various components of the metabolic syndrome. $\mathrm{N}$. sativa is a remedy that may prove to be useful in the prevention and treatment of the insulin resistance syndrome. (Ahmad Najmi et al 2008)

Recently independent clinical studies published in the archives of AIDS also established some astonishing effects of black seed on the defense system by improving the ratio between helper $\mathrm{t}$-cells and suppresser $\mathrm{t}$-cells by a significant amount while also enhancing the natural killer cell activity. (Dr. Hwyda Arafat 2008)

On the basis of the above facts it may be concluded that Kalonji seeds is a potential drug having multiple pharmacological effects as claimed by Unani System of Medicine. There is need to give more stress on further research on the present findings to find treatment of many life style diseases affecting Human beings.

\section{Conclusion}

It has been scientifically proved that the immunity system is the only system that has the ability to combat diseases and produce cells that kill viruses. Based on these facts, we can conclude that the Kalonji/Black Seed may be a cure for every disease because it strengthens the immunity system which is responsible for curing diseases and combating viruses. By taking extensive clinical research on Kalonji we can find treatment for many life style diseases like arthritis, diabetes mellitus, hypertension, heart disease etc and life threatening diseases like tumors, cancer, AIDS etc.

\section{References}

1. Chaudhry NMA, Tariq P. In Vitro Antibacterial activities of Kalonji, Cumin and Poppy Seed. Pak. J Bot. 2008; 40(1): 461-67.

2. Najmi A. Effect of Nigella sativa oil on various clinical and biochemical parameters of insulin resistance syndrome. Int. Journal Diabetes Developing Countries. 2008; 28(1): 11-4 doi: 10.4103/0973-3930.41980

3. Arafat H. Traditional herbal medicine kills pancreatic cancer cells, researchers report May 19, 2008.

4. Sangi S. A new and novel treatment of opioid dependence: Nigella sativa 500 mg. J Ayub Med Coll Abbottabad. 2008; 20(2): 118-24.

5. Tehranipour M, Monavar $\mathrm{N}$. The preventive effect of $\mathrm{N}$-butanol fraction of Nigella sativa on ethylene glycol-induced kidney calculi in rats. Pharmacogn Mag. 2011; 7(28): 338-43. doi: 10.4103/0973-1296.90416

6. Gilani $\mathrm{AH}$. Bronchodilator, spasmolytic and calcium antagonist activities of Nigella sativa seeds (Kalonji). The Journal of the Pakistan Medical Association. 2001; 51(3): 115-120.

7. Al-Jawad FH. Broncho-relaxant activity of Nigella sativa versus anthemis nobilis in chronic bronchial asthma; a comparative study of efficacy. IOSR Journal of pharmacy. 2012; 2(4): 81-83. 